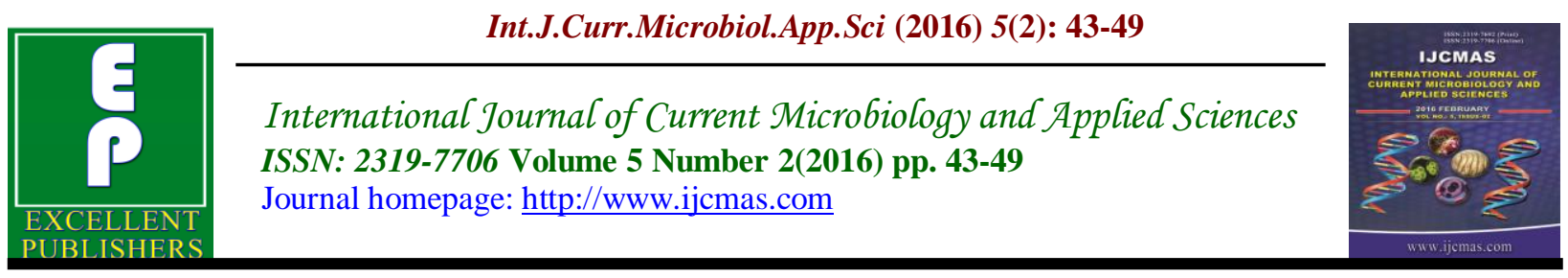

Original Research Article

http://dx.doi.org/10.20546/ijcmas.2016.502.004

\title{
Moringa oleifera in Vitro Culture and its Application as Anti-Diabetic in Alloxan Induced Diabetic Albino Mice
}

\author{
Asma G. Oriabi* \\ College of applied biotechnology, Al-Nahrian university, Baghdad, Iraq \\ *Corresponding author
}

\begin{abstract}
A B S T R A C T
Keywords

Moringa oleifera,

Anti-diadetic,

Plant tissue

culture,

Alloxan.

Article Info

Accepted:

09 January 2016

Available Online:

10, February 2016

This work is aimed to indicate the anti-diabetic effect of ethanol extract of Moringa oleifera leaves and callus tissues in alloxan induced diabetic albino mice. Eighteen albino mice were randomly grouped into eight groups. The first and second one were positive and negative groups, other six groups were treated with ethanol extract in different concentration $(20 \%, 40 \%$ and $80 \%$ ) for both leaves and callus tissues. Results revealed that the highest mean callus growth obtained at $0.5 \mathrm{mg} / 1 \mathrm{BA}$ and $2.5 \mathrm{mg} / 12,4-\mathrm{D}(779.5 \mathrm{mg})$. Results also showed that ethanol extract of callus tissues significantly reduce glucose level in the blood of the treated albio mice recording 113.3 $\mathrm{mg} / \mathrm{Ld}$ at the day 15 of the treatment. Weight of the treated animals significantly increased in all treatment begin from day 7 compared with negative control.
\end{abstract}

\section{Introduction}

Diabetes mellitus is a prevalent disease affecting the population of most of the countries in the world. This disease is caused by the abnormality in carbohydrate metabolism which could be due to low insulin secretion or insensitivity of target organs to insulin (Sugunabai et al.,, 2014). In diabetes, lipid abnormalities, anemia, alteration of liver and kidney functional indices has been implemented as major risk factors to the progression of both microvascular and macrovascular diabetes complications, people suffering from diabetes cannot produce or properly use insulin, and so they persistently have high blood glucose (Aja et al.,, 2015).

Plants are well known in traditional medicine for their hypoglycaemic effects and available literature indicates that there are more than 800 plant species showing hypoglycaemic activities in vivo. The maximum therapeutic and minimum side effects of herbal remedies have been verified in numerous scientific investigations. Also, plant materials play major roles in primary health care as therapeutic remedies in many 
developing countries (Jogender et al.,, 2013).

It has become imperative to investigate plants such as Moringa oleifera and Vernonia amygdalina which have been used by native populations as hypoglycaemic agents in a standardized experimentation. A number of investigations have shown that saponins, flavonoids and a host of other secondary plant metabolites including arginine and glutamic acid possess hypoglycemic effect in various animal models and have been found to be hepatoprotective in diabetic animal experiments (Efiong et al.,, 2013).

Moringa oleifera has become very important so its contain 18 of the 20 amino acid that the human body required and is one of the plant species with higher seed oil content, between 30-40\% (Cartes and Delaveau, 2014).

Tissue culture has been utilized extensively for mass propagation of economically important or elite plants, as well as species that are endangered due to extinction (Salema et al.,, 2007). Moringa oleifera callus induction was a greatly influenced by temperature, nutrients, $\mathrm{pH}$ and addition of ascorbic acid in the growing medium, Furthermore, the seeds contain an essential oil (Bennett et al.,, 2003). Stephenson and Fahey (2004) reported that 20\% success rate of germination of immature seeds with subsequent shoot development from the epicotyl meristematic tissues of $M$. oleifera Lam. cultured on Murashige and Skoog (MS) semi-solid medium (Murashige and Skoog 1962) amended with $1 \mathrm{mg} / \mathrm{L}$ benzylaminopurine (BAP) and $1 \mathrm{mg} / \mathrm{L}$ gibberellic acid (GA3) and the success rate of seed germination was increased to $73 \%$ when immature seed explants were inoculated on membrane raft in MS liquid medium of the same media formulation, with the number of shoots regenerated roughly comparable to the semi-solid medium.

\section{Materials and Methods}

\section{Materials}

The chemicals and reagents used are of analytical quality. Fresh leaves of fully grown Moringa oleifera were collected from a green house at the college of applied biotechnology, Al-Nahrian university, Baghdad, Iraq.

\section{Method}

\section{Callus Induction and Growth}

Seeds of M. oleifera were washed with running water for 15 minutes; surface sterilized with 50\% Clorox solution for 20 minutes, and then rinsed three times with sterile distilled water. The seeds after dipping in $99 \%$ ethanol, and removing the seed coats were cultured on MS agar medium containing $4.0 \mathrm{mg} / \mathrm{l} \mathrm{BA}$ for seed germination, then shoot explants were cut into the small pieces and placed on the MS agar medium supplemented with $0.0,0.5$, 1.0 or $1.5 \mathrm{mg} / \mathrm{l}$ BA and $0.0,1.5,2.0$ or $2.5 \mathrm{mg} / 1$ 2, 4-D for six weeks. All cultures were incubated at $25 \pm 2^{\circ} \mathrm{C}$. Callus induction frequency $(\%)$ was calculated using the following formula (Yousif. 2002) .

(No. of seeds produced callus/total seeds cultured)*100. For callus growth, the induced calli (initial weight was 150 $\mathrm{mg} /$ tube) were sub-cultured, on the same medium.

\section{Preparation of Extracts}

The leaves and callus pieces of Moringa oleifera were dried in oven at $40^{\circ} \mathrm{C}$. The dried tissues were grinding well then the powder was soaked in $70 \%$ ethanol at room 
temperature for 24 hours, filtered and evaporated to dryness using rotator evaporator.

\section{Induction of Diabetes and Animals Treatment with Extracts}

Alloxan $100 \mathrm{mg} / \mathrm{kg}$ of body weight was used to induce diabetes. Mice were injected intraperitoneally. The dose was prepared by dissolving $0.2 \mathrm{ml}$ alloxan in $0.9 \mathrm{NaCl}$ solutions. A solution of $5 \%$ glucose was administered orally. Blood glucose was observed 20 hours after alloxanistion (Sushruta et al.,, 2006). In this study there was eight groups of treatment: +control group (non-treated with alloxan), -control group (treated with alloxan), other six groups treated with 20\%, $40 \%$ and $80 \%$ either of Moringa oliefera leaves or callus ethanol extracts.

\section{Blood Samples Collection and Determination of Animals Weight}

The blood samples were collected from the tail vein puncture for measurement of blood glucose in all mice groups. Glucometer then used for determination the Glucose level. Animals weight were determined using sensitive balance.

\section{Results and Discussion}

Results displayed in table 1 revealed that 0.5 and $1.0 \mathrm{mg} / \mathrm{l} \mathrm{BA}$ significantly increase the mean $\%$ callus induction recording 57.575 and $45.25 \%$ respectively compared with $0.0 \mathrm{mg} / \mathrm{l} \mathrm{BA}(20.425 \%)$, the highest mean percentage of callus induction obtained at $0.5 \mathrm{mg} / \mathrm{l} \mathrm{BA}$, due to the effect of $2,4-\mathrm{D}$ the mean $\%$ callus induction increased significantly at $1.5,2.0$ and $2.5 \mathrm{mg} / 12,4-\mathrm{D}$ with mean values 38.3, 60.7 and $60 \%$ respectively compared with $0.0 \mathrm{mg} / \mathrm{l} 2,4-\mathrm{D}$ $(0.0 \%)$ and the highest mean recorded at 2.0mg/l 2,4-D (60.7\%). The interaction between 2,4-D and BA indicated that $0.5 \mathrm{mg} / 1 \mathrm{BA}$ and $2.5 \mathrm{mg} / 1$ 2,4-D recording the highest percentage of callus induction $(93.5 \%)$. Data showed in table 2 exhibited that 0.5 and $1.0 \mathrm{mg} / \mathrm{l} \mathrm{BA}$ increased the mean callus fresh weight significantly (367.46 and $331.64 \mathrm{mg}$ respectively) compared with 0.0 and $1.5 \mathrm{mg} / \mathrm{l}$ BA (168.82 and $288.16 \mathrm{mg}$ respectively) and the highest mean callus fresh weight obtained at $0.5 \mathrm{mg} / 1 \mathrm{BA}$ while mean callus fresh weight increased significantly with the increasing 2,4-D concentration recording $0,219.325,341.95$, 380.8 and $503.025 \mathrm{mg}$ in $0.0,1.0,1.5,2.0$ and $2.5 \mathrm{mg} / 1$ 2,4-D respectively. The interaction revealed that the highest mean callus fresh weight obtained at $0.5 \mathrm{mg} / 1 \mathrm{BA}$ and $2.5 \mathrm{mg} / 1$ 2,4-D with mean value $779.5 \mathrm{mg}$, these results was agreed with those of Hussian et al., (2010) who investigated that callus induction increased with increasing 2,4-D concentration. Callus, mainly comprising masses of undifferentiated cells, is good starting material for in vitro manipulation (Oriabi, 2013). But these results was disagreement with those obtained by Shank et al., (2013) who reported that MS medium supplemented with $0.5 \mathrm{mg} / \mathrm{l}$ of $2,4-\mathrm{D}$ was the most effective medium for callus induction of $M$. oleifera with $100 \%$ of callus induction from week-3 after culturing of shoot, Figure 1 showing the callus mass of $M$. oleifera which grown on MS medium after two subcultures.

Results in table 3 described the changes in the weight of animals based on varying extract doses during the 15 days of treatment and showed that the body weight of mice significantly increased in the positive control group and those treated with 20, 40 and $80 \%$ of $M$. oleifera leaves or callus extracts compared with negative control which was significantly decreased with 
increasing days of treatment, these results was agreement with those obtained by Aja $e t$ al., (2013) who reported a significant $(\mathrm{P}<0.05)$ reductions in the mean body weight of rats in diabetic control compared to positive group while rats in treated groups showed significant $(\mathrm{P}<0.05)$ increase in their mean body weight compared to diabetic control group in work done earlier on antidiabetic effect of aqueous extract of
Moringa oleifera and Bridelia ferruginea leaves in alloxan-induced diabetic albino rats. Data displayed in table 4 show that administration of Moringa oleifera ethanol extracts of either leaves or callus tissues in alloxan induced diabetic albino mice at various doses of 20,40 and $80 \%$ reduce the blood glucose level in the treated mice significantly compared to the negative control.

Table.1 Effect of the Interaction between 2,4-D and BA on the Mean of \% Callus Induction, after Inoculating Explants onto Solid MS Medium for Four Weeks, n=30

\begin{tabular}{|c|c|c|c|c|c|}
\hline $\begin{array}{c}\text { 2.4-D(g/l) } \\
\text { BA(mg/l) }\end{array}$ & 0.0 & 1.5 & 2.0 & 2.5 & Mean \\
\hline 0.0 & & & & & \\
\hline 0.5 & 0 & 19.8 & 28.1 & 33.8 & 20.425 \\
\hline 1.0 & 0 & 48.9 & 73.6 & 93.5 & 57.575 \\
\hline 1.5 & 0 & 21.3 & $\mathbf{6 8 . 2}$ & $\mathbf{5 3 . 2}$ & 45.25 \\
\hline Mean & $\mathbf{0}$ & $\mathbf{3 8 . 3}$ & $\mathbf{6 0 . 7}$ & $\mathbf{6 0}$ & \\
\hline LSD 0.05 & $\mathbf{2 , 4 - D}=\mathbf{6 . 0 1}$ BA $=\mathbf{6 . 3 5}$ Interaction $=\mathbf{2 0 . 0 4}$ & \\
\hline
\end{tabular}

Table.2 Effect of 2,4-D and BA on the Mean Callus Fresh Weight (mg), after Inoculating Callus Pieces onto Solid MS Medium for Five Weeks. Initial Weight was 100mg. n= 30

\begin{tabular}{|l|c|c|c|c|c|r|}
\hline $\begin{array}{l}\text { 2,4-D(g/l) } \\
\text { BA(mg/l) }\end{array}$ & 0.0 & 1.0 & 1.5 & 2.0 & 2.5 & Mean \\
\hline 0.0 & & & & & & \\
\hline 0.5 & 0 & 113.1 & 261.3 & 185.3 & 284.4 & 168.82 \\
\hline 1.0 & 0 & 178.3 & 352.1 & 527.4 & 779.5 & 367.46 \\
\hline 1.5 & 0 & 301.7 & 422.5 & 371.9 & $\mathbf{5 6 2 . 1}$ & $\mathbf{3 3 1 . 6 4}$ \\
\hline Mean & 0 & $\mathbf{2 8 4 . 2}$ & $\mathbf{3 3 1 . 9}$ & $\mathbf{4 3 8 . 6}$ & $\mathbf{3 8 6 . 1}$ & $\mathbf{2 8 8 . 1 6}$ \\
\hline LSD 0.05 & $\mathbf{0}$ & $\mathbf{2 1 9 . 3 2 5}$ & $\mathbf{3 4 1 . 9 5}$ & $\mathbf{3 8 0 . 8}$ & $\mathbf{5 0 3 . 0 2 5}$ & \\
\hline
\end{tabular}


Table.3 Effect of Extract Doses on the Weight of Alloxan Induced Diabetic Albino Mice after 15 Days of Treatment, $n=10$

\begin{tabular}{|c|c|c|c|c|c|c|c|c|c|}
\hline \multirow{2}{*}{$\begin{array}{l}\text { Type of } \\
\text { Treatment } \\
\text { Days }\end{array}$} & \multirow{2}{*}{$\begin{array}{l}\mathrm{mg} / \mathrm{Ld} \\
+ \\
\text { control }\end{array}$} & \multirow{2}{*}{$\begin{array}{l}\text { mg/Ld } \\
- \\
\text { control }\end{array}$} & \multicolumn{3}{|c|}{ Leaves extract } & \multicolumn{3}{|c|}{ Callus extract } & \multirow{2}{*}{$\begin{array}{l}\text { mg/Ld } \\
\text { Mean }\end{array}$} \\
\hline & & & $20 \%$ & $40 \%$ & $80 \%$ & $20 \%$ & $40 \%$ & $80 \%$ & \\
\hline 1 & 26.86 & 26.91 & 26.58 & 26.59 & 26.69 & 26.76 & 26.82 & 26.65 & 26.75 \\
\hline 2 & 26.84 & 26.87 & 26.53 & 26.53 & 26.84 & 26.59 & 26.81 & 26.89 & 23.75 \\
\hline 3 & 26.94 & 26.89 & 26.72 & 26.73 & 26.89 & 26.74 & 26.93 & 26.78 & 26.82 \\
\hline 4 & 26.89 & 26.62 & 26.79 & 26.69 & 26.93 & 26.82 & 26.97 & 26.88 & 26.82 \\
\hline 5 & 26.93 & 26.29 & 26.77 & 26.84 & 26.99 & 26.95 & 26.89 & 27.06 & 26.84 \\
\hline 6 & 27.36 & 26.01 & 26.68 & 26.78 & 26.96 & 26.87 & 26.96 & 27.11 & 26.84 \\
\hline 7 & 27.54 & 25.79 & 26.85 & 26.89 & 27.05 & 26.97 & 26.96 & 27.17 & 26.90 \\
\hline 8 & 27.63 & 25.81 & 26.89 & 26.96 & 27.09 & 26.95 & 26.98 & 27.32 & 26.95 \\
\hline 9 & 27.69 & 25.52 & 26.89 & 26.95 & 27.13 & 27.03 & 26.99 & 27.68 & 26.98 \\
\hline 10 & 27.83 & 25.32 & 26.83 & 26.98 & 27.22 & 27.02 & 26.98 & 27.85 & 27.03 \\
\hline 11 & 27.89 & 25.21 & 26.97 & 27.01 & 27.48 & 27.14 & 27.21 & 27.95 & 27.10 \\
\hline 12 & 28.11 & 25.08 & 26.94 & 27.19 & 27.65 & 27.32 & 27.32 & 27.98 & 27.19 \\
\hline 13 & 28.27 & 24.95 & 26.89 & 27.37 & 27.93 & 27.52 & 27.37 & 28.24 & 27.31 \\
\hline 14 & 28.27 & 24.38 & 27.48 & 27.59 & 28.07 & 27.59 & 27.78 & 28.36 & 27.44 \\
\hline 15 & 28.74 & 24.17 & 27.73 & 27.68 & 28.15 & 27.63 & 28.09 & 28.58 & 27.59 \\
\hline Mean & 27.58 & 25.73 & 26.90 & 26.98 & 27.27 & 27.06 & 27.13 & 27.5 & \\
\hline $\begin{array}{ll}\text { LSD } & 0.05\end{array}$ & \multicolumn{9}{|c|}{ Day $=1.09 \quad ;$ treatment type $=0.62$} \\
\hline
\end{tabular}

Figure.1 Moringa oleifera Callus Cultures Originated from Shoot Explants, Showing the Callus Mass Grown on MS Medium for Eight Weeks

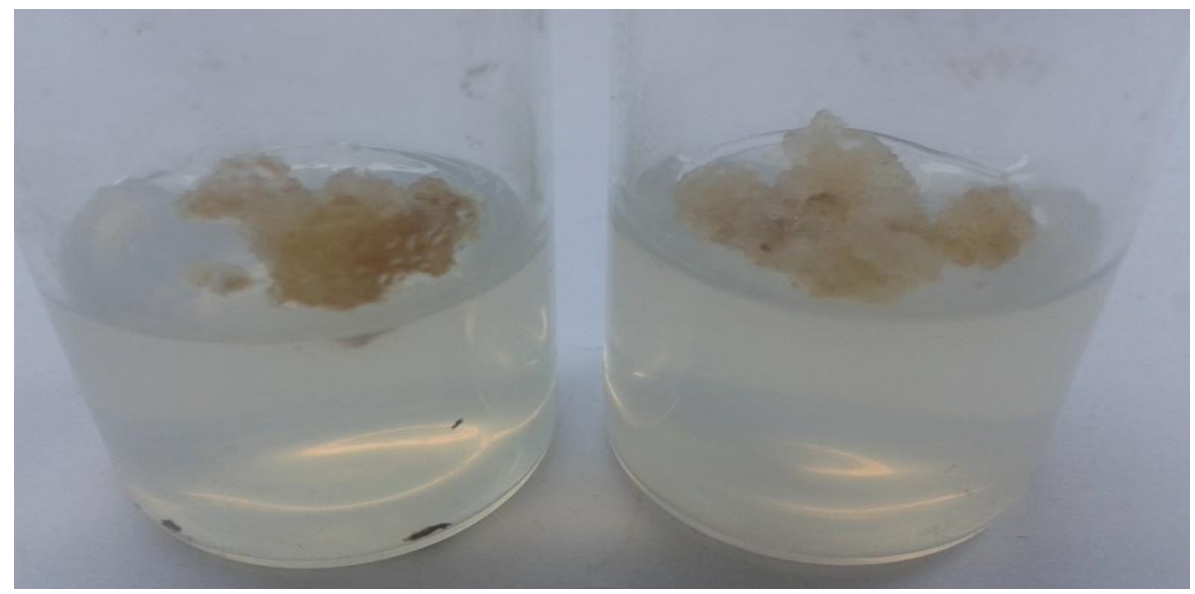


Table.4 Effect of Extract Doses on the Blood Glucose Level in Alloxan Induced Diabetic Albino Mice after 15 Days of Treatment, $n=10$

\begin{tabular}{|c|c|c|c|c|c|c|c|c|c|}
\hline \multirow{2}{*}{$\begin{array}{l}\text { Type of } \\
\text { Days }\end{array}$} & \multirow{2}{*}{$\begin{array}{l}\text { mg/Ld } \\
+ \\
\text { control }\end{array}$} & \multirow{2}{*}{$\begin{array}{l}\text { mg/Ld } \\
- \\
\text { control }\end{array}$} & \multicolumn{3}{|c|}{ Leaves extract } & \multicolumn{3}{|c|}{ Callus extract } & \multirow{2}{*}{$\begin{array}{l}\text { mg/Ld } \\
\text { Mean }\end{array}$} \\
\hline & & & $20 \%$ & $40 \%$ & $80 \%$ & $20 \%$ & $40 \%$ & $80 \%$ & \\
\hline 1 & 123.1 & 321 & 317.5 & 329.5 & 319.3 & 328.5 & 315.9 & 312.7 & 295.9 \\
\hline 2 & 131.4 & 352.1 & 323.8 & 319.5 & 304.1 & 332.1 & 309.4 & 319.3 & 298.9 \\
\hline 3 & 119.2 & 329.5 & 313.9 & 349.2 & 309.2 & 320.4 & 304.1 & 289.2 & 291.8 \\
\hline 4 & 134.1 & 382.3 & 315.7 & 326.8 & 285.2 & 318.9 & 284.6 & 269.4 & 289.6 \\
\hline 5 & 122.2 & 368.7 & 342.3 & 314.8 & 293.8 & 311.7 & 279.8 & 279.5 & 289.1 \\
\hline 6 & 115.3 & 359.4 & 328.3 & 321.5 & 269.6 & 315.3 & 268.7 & 248.9 & 278.3 \\
\hline 7 & 121.1 & 397.1 & 339.7 & 312.3 & 275.8 & 321.6 & 258.2 & 253.4 & 284.9 \\
\hline 8 & 118.9 & 409.6 & 316.1 & 318.7 & 265.8 & 317.9 & 236.8 & 232.1 & 276.9 \\
\hline 9 & 124.7 & 401.7 & 326 & 342.1 & 2598 & 312.6 & 239.5 & 229.6 & 279.5 \\
\hline 10 & 109.6 & 423.6 & 348.2 & 338.2 & 276.8 & 308.7 & 227.4 & 223.8 & 282.3 \\
\hline 11 & 121.5 & 452.8 & 329.8 & 313.8 & 231.3 & 317.9 & 224.1 & 205.3 & 274.5 \\
\hline 12 & 119.8 & 509 & 353.9 & 312.8 & 238.9 & 313.5 & 221.6 & 178.2 & 280.9 \\
\hline 13 & 118.4 & 493.5 & 323.1 & 309.4 & 226.9 & 303.2 & 213.1 & 152.3 & 267.4 \\
\hline 14 & 132.7 & 501.7 & 319.5 & 298.7 & 221.7 & 285.1 & 207.9 & 131.9 & 262.4 \\
\hline 15 & 117.3 & 513.4 & 326.1 & 277.4 & 216.2 & 262.4 & 211.8 & 113.3 & 254.7 \\
\hline Mean & 121.9 & 414.3 & 328.2 & 318.9 & 266.2 & 311.3 & 253.5 & 229.2 & \\
\hline LSD 0.05 & \multicolumn{9}{|c|}{ Day $=21.96 ;$ treatment type $=18.53 ;$ Day $*$ treatment type $=38.62$} \\
\hline
\end{tabular}

But callus extract was more effective than those of leave extracts in returning the animal's body weight and blood glucose level to the normal in comparison to negative control, using plant extracts for diabetic treatment appeared to be generally safe due to the presence of bioactive compounds especially in those of medicinal plants which have hypoglycemic effects through reduction insulin resistant, induction the releasing and inhibition glucagon secretion, slowing down the digestion and absorption of carbohydrates or by decreasing hepatic glucose production (Aja et al.,,2015). M. oleifera as a medicinal plant contains flavonoids, stilbeans, terpenoids, glycoside and alkaloids as its bioactive compounds as mentioned by Gupta and Misra, (2006), which also reported that the anti-diabetic effect of $M$. oleifera caused by an increase in insulin output or by inhibition of the intestinal absorption glucose. With the induction of callus cultures variable changes may occurred in the metabolic reactions of the growing cells and lead increase in their yield and activity

\section{References}

Aja, P. M., Igwenyi, I. O., Ugwu Okechukwu, P. C., Orji, O. U. and Alum. E.U. (2015). Evaluation of Antidiabetic Effect and Liver Function Indices of Ethanol Extracts of Moringa oleifera and Cajanus cajan Leaves in Alloxan Induced Diabetic Albino Rats. Global Veterinaria, 14 (3): 439-447.

Aja, P. M., Nwafor, E.J., Ibiam, A.U., Orji, O.U., Aja, P.M., Nwafor, E.J., Ibiam, A.U., Orji, O.U., Ezeani, N. and Nwali, B.U. (2013). Evaluation of Anti-diabetic and Liver Enzymes Activity of Aqueous Extracts of Moringa oleifera and Brideliaferruginea Leaves in Alloxan Induced Diabetic Albino Rats. Inter. J. 
Biochemistry Research \& Review, 3(3): 248-258.

Bennet, R. N., Mellon, F. A., Foidl, N., Pratt, J. H., Dupont, M. S., Perkines, L. and Kroon, P. A. (2003). Profiling glucosinolates and phenolics in vegetative and reproductive tissues of the multi-purpose trees Moringa oleifera L. (Horseradish tree) and Moringa stenopetala L. J Agric. Food Chem., 57:3546-3553.

Cartes, P. and Delaveau, C. (2014) In vitro culture of Moringa oleifera, multipurpose specie for Chile. $J$. Biotechnol Biomater., 3(5): 307.

Efiong, E. E., Igile, G. O., Mgbeje, B. I. A., Out, E. A. and Ebong, P. E. (2013). Hepatoprotective and anti-diabetic effect of combined extracts of Moringa oleifera and Vernonia amygdalina in streptozotocin-induced diabetic albino Wistar rats. J. Diabetes Endocrinol, 4(4): 45-50.

Gupta, A. K. and Misra, N. (2006). Hepatoprotective Activity of aqueous ethanolic extract of hamonile capitula in paracetamol intocicated albino rats. Americ. J. Pharmaco. Toxico., 1: 17-20.

Hussain, Z., Khan, M. H., Bano, R., Rashid, H. and Chaudhry, Z. (2010). Protocol optimization for efficient callus induction and regeneration in three Pakistani rice cultivars. Pak. J. Bot., 42(2): 879-887.

Jogender, S., Saurabh, A. and Sumer, S. (2013). In vitro Regeneration of Moringa oleifera: A Pharmaceutical Important Shrub. Asian J. Biochem. and Pharmac. Res., 1 (3): 2231-2560.

Murashige, T. and Skoog. (1962). A revised medium for rapid growth and bioassays with Tobacco tissue culture. Physiol. Plant. 15: 473-497.

Oriabi, G. A. (2013). Investigation of Growth Factors and DNA Markers for Drought Tolerance in Some Rice (Oryza sativa L.) Genotypes. $\mathrm{PhD}$ thesis, College of Science. Al-Nahrian University. Baghdad, Iraq.

Salema, V. F., Senpati, S. K. and Rout, G. R. (2007). Rapid clonal propagation of Curculigo orchioides Gaertn., an endangered medicinal plants. In-vitro Cell Dev. Biol-Plants, 43(2):140-143.

Shank, L. P., Riyathong, T., Lee, V. S.and Dheeranupattana, S. (2013). Peroxidase Activity in Native and Callus Culture of Moringa Oleifera Lam. J. Medical and Bioengineering. 2( 3) :163-167.

Stephenson, K. K. and Fahey, J. W. (2004). Development of tissue culture methods for the rescue and propagation of endangered Moringa spp. germplasm. Econ. Bot. 58 (3): 116-124.

Sugunabai, J., Jayaraj, M., Karpagam, T. and Varalakshmi, B. (2014). Anti-diabetic efficiency of Moringa oleifera and Solanum nigrum. Int. J. Pharm Sci., 6(1): 40-42.

Sushruta, K., Satyanarayana, S., Srinivas, N., and Raja Sekhar, J. (2006). Evaluation of the blood-glucose reducing effects of aqueous extracts of the selected umbelliferouse fruits used in culinary practices. Trop . J. pharm. Res., 5(2): 613617.

Yousif, S. (2002). Evaluation and regeneration salt tolerant rice plant using different techniques. $\mathrm{PhD}$ thesis, Agricultural College. Baghdad University. Baghdad, Iraq.

\section{How to cite this article:}

Asma G. Oriabi. 2016. Moringa oleifera in Vitro Culture and its Application as Anti-Diabetic in Alloxan Induced Diabetic Albino Mice. Int.J.Curr.Microbiol.App.Sci.5(2): 43-49. doi: http://dx.doi.org/10.20546/ijcmas.2016.502.004 